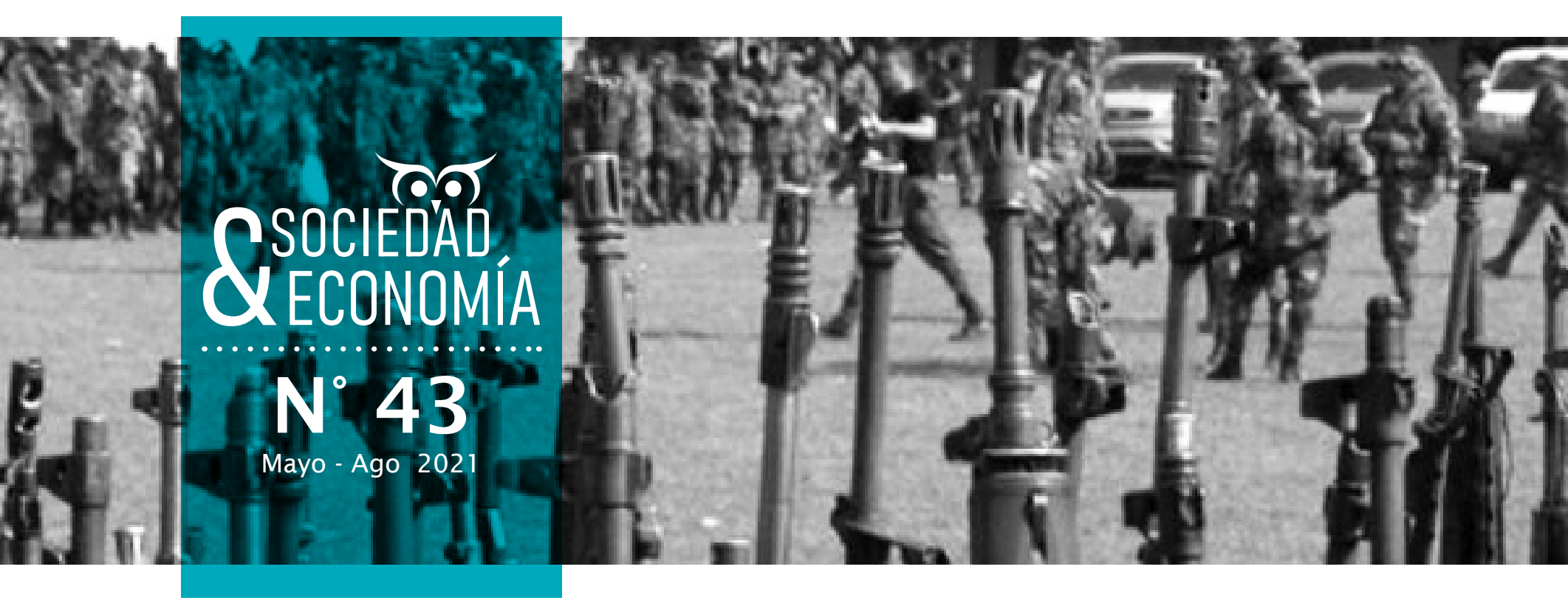

\title{
Paramilitarismo, discurso autoritario y clase política en Caldas, 1978-2006
}

Paramilitarism, Authoritarian Discourse and Political Class in Caldas, 1978-2006

Julio Cruz'

Universidad Católica de Pereira, Pereira, Colombia.

식ulio.cruz@ucp.edu.co

(D) https://orcid.org/0000-0002-5867-6930

Recibido: 21-05-2020

Aceptado: 28-09-2020

Publicado: 01-05-2021

1 Magíster en Estudios Políticos. 


\section{Resumen}

Se aborda la escena política del departamento de Caldas desde la constitución de la Coalición barcoyepista hasta la desmovilización de las AUC, centrado en la influencia que tuvo en la reconfiguración de las relaciones de poder los vínculos de políticos profesionales con los grupos paramilitares presentes en la región. Se propone como objetivo captar los despliegues históricos que permitan postular una transformación de las relaciones de poder en el mencionado departamento. La metodología está construida sobre la base de la propuesta de Michel Foucault en torno al concepto de poder, se llevó a cabo un análisis documental de textos hallados sobre paramilitarismo y clase política, en Caldas, en el periodo descrito. Las principales conclusiones apuntan a que se muestra el giro político del departamento hacia el autoritarismo, la desarticulación de la Coalición y las secuelas de la presencia paramilitar aún después de su desmovilización.

Palabras clave: autoritarismo; coalición barcoyepista; giro político; relaciones de poder; paramilitarismo.

\section{Abstract}

The political scene of the Department of Caldas is addressed from the constitution of the Barcoyepista Coalition to the demobilization of the AUC, focusing on the influence that the links of professional politicians with the paramilitary groups present in the region had on the reconfiguration of power relations. The objective is to capture the historical unfolding that allows us to postulate a transformation of power relations in the Department of Caldas. The methodology is based on Michel Foucault's proposal on the concept of power; a documentary analysis of texts found on paramilitarism and political class in Caldas, in the described period, was carried out. The main conclusions showed the political turn of the department towards authoritarianism, the disarticulation of the Coalition and the aftermath of the paramilitary presence even after its demobilization.

Keywords: Authoritarianism; barcoyepista coalition; political turn; political relations; paramilitarism.

\section{Finaciación}

Este artículo de investigación es producto de la tesis para optar al título de magíster en Estudios Políticos de la Universidad de Caldas, titulada: "La secta del fénix. La formación discursiva del paramilitarismo en Caldas, 1980-2006”, investigación ya concluida.

\section{Conflicto de interés}

El autor declara no tener ningún conflicto de interés en la publicación de este artículo.

\section{(c) (i) Este trabajo está bajo la licencia Atribución-No-Comercial 4.0 Internacional}

¿Cómo citar este artículo?

Cruz, J. (2021). Paramilitarismo, discurso autoritario y clase política en Caldas, 1978-2006. Sociedad y economía, (43), e1039779. https://doi.org/10.25100/sye.v0i43.9779 


\section{Introducción}

La relación entre clase política, élites y paramilitarismo en el departamento de Caldas, se analizó desde la conformación de la llamada Coalición barcoyepista, en 1978, hasta la desmovilización de las Autodefensas Unidas de Colombia (AUC), en 1997. El país atravesaba un momento político tenso: era la época del Estatuto de seguridad de Turbay, el crecimiento de los grupos guerrilleros, la consiguiente respuesta paramilitar en regiones como el Magdalena Medio y la emergencia del fenómeno del narcotráfico. En materia política, operaba una especie de pacto tácito entre el centro y las regiones, heredado del Frente Nacional, y según el cual la clase política nacional no intervenía en las dinámicas de las regiones. Como hipótesis se asume la idea de que el arribo de las estructuras paramilitares a Caldas reconfiguró las relaciones de poder en el departamento, lo que influyó decisivamente en la desarticulación de la Coalición y la emergencia de nuevos liderazgos fuertemente influidos por el discurso autoritario. Para llevar a cabo el estudio, se apeló a una extensa revisión documental sobre el tema tratado, en particular el archivo físico del diario manizaleño La Patria; pero también se tuvieron en cuenta trabajos académicos, de organizaciones sociales y portales virtuales sobre el conflicto armado en Colombia, entre otros. Por motivos de espacio, no se presentará aquí la totalidad de artículos de prensa que fueron revisados en la investigación, y se dará prioridad a los hallazgos académicos, que hacen las veces de antecedentes de investigación, si bien se aclara que el relato del paramilitarismo en Caldas sigue ausente.

En términos teóricos y metodológicos, el texto se sustenta en los postulados de Foucault (2003), para lo que respecta al concepto de poder, entendido como relaciones de fuerza inmanentes a los sujetos, intencionales, no subjetivas y provenientes de abajo, es decir, de las relaciones mismas, cuyo referente no es algo que se adquiere, sino que se ejerce (Foucault, 2007, pp. 114-116). Deleuze (1987) expone esto mismo en forma de postulados: propiedad, localización, subordinación, esencia y atributo, modalidad, legalidad (pp. 51-56), y agrega que los enunciados, como singularidades, solo se establecen como discurso gracias a las relaciones de poder que los congregan y que forman la curva enunciativa: "el poder (...) con relación al saber, produce verdad, en la medida en que hace ver y hace hablar" (p. 112). Igualmente, se tiene en cuenta que la relación entre poder y saber se establece de forma recíproca, dialéctica si se quiere: todo saber se establece sobre la base de unas relaciones de poder y todo poder implica un campo de saber, "el poder produce saber" (Foucault, 2008, p. 34; también citado por Deleuze, 1987, p. 65).

Para la comprensión del concepto de élites, se acudió a Bobbio (1982), quien asegura que "todos los gobiernos que existieron y los que existirán han sido siempre gobiernos de pocos, gobiernos de minorías organizadas, o de élites" (p. 1119), ergo, son oligárquicos. Las élites son entendidas como aquellos grupos sociales que ocupan los estratos sociales superiores en términos de poder y riqueza, y las élites políticas como las que tienen la capacidad de tomar decisiones que afectan a los miembros del grupo al que pertenecen (Bolívar-Meza, 2002). Las élites regionales son el resultado de un determinado despliegue de las relaciones de poder, no su expresión pura y prístina, la forma como dicho poder trata de fijarse, de estabilizarse, de hacerse permanente, en medio de su natural condición inestable, cambiante, móvil. Estas élites son, en últimas, una estrategia de dominación resultado de la dinámica concreta y particular de unas relaciones de poder situadas y específicas. Igualmente ocurre con las instituciones del Estado y con las leyes que lo soportan, tanto a este como a las formas de dominación más allá de las militares y físicamente violentas. Lo que las élites despliegan es una microfísica del poder en los intersticios de la oficialidad y la corporeidad (Foucault, 2008, p. 33).

En cuanto al concepto de paramilitarismo, sus integrantes son definidos como ejércitos armados privados, conformados por civiles que actúan como carne de cañón en la lucha contrainsurgente (Medina, 1990, p. 184), que llevan a cabo operaciones de limpieza política y consolidación militar para preparar el dominio 
territorial (Romero, 2003, p. 38); cuyo blanco, además de la insurgencia, está constituido por la izquierda política y los movimientos sociales, considerados como base social de aquella (Zelik, 2015, pp. 23-24). Lo que los involucra en la categoría de terrorismo de Estado (Velásquez, 2007, p. 137).

Su característica general en relación con el Estado es que tienen una cercanía con este, sea de tolerancia o conformación, directa o indirecta (Kalyvas y Arjona, 2005, p. 29), y en este orden de ideas se le subordinan (Duncan, 2015, pp. 274-275), sin que hagan parte de la institucionalidad, como indica su nombre (Giraldo, 2004, p. 7; Rivas y Rey, 2008, p. 49). Poseen un carácter ofensivo y un horizonte ideológico (García-Pérez, 2016, p. 238), vinculado al autoritarismo ultraconservador de extrema derecha, al menos para el caso colombiano, e involucran otros sectores sociales además del Estado, particularmente productores privados (García-Peña, 2005, p. 65; Melo, 1990, p. 510 ; Reyes-Posada, 1991, p. 36).

En primera instancia, y de la manera más elemental, el paramilitarismo es simplemente una estrategia militar. Dicha estrategia consiste en configurar un grupo de hombres armados que actúan al margen de y paralelamente a las fuerzas oficiales; de allí su nombre. La segunda dimensión del paramilitarismo es la que lo cataloga como un dispositivo político (Foucault, 1985). En efecto, dicha estrategia no puede calificarse exclusivamente como militar, en la medida en que los propósitos que se traza van más allá del ámbito particular y competen a toda la población, las instituciones, los discursos, las normas codificadas y demás elementos que confluyen reticularmente para constituir una realidad política. La tercera dimensión del paramilitarismo es la que lo determina como una tecnología de poder aplicada al conflicto económico moderno, esto es, a la lucha de clases (Foucault, 2008). Toda vez que el paramilitarismo surge en un ámbito moderno y se apoya en la razón de Estado, se deriva de allí que su proceder busque reconfigurar las relaciones de poder en torno a determinados regímenes de verdad que conlleven la defensa de aquello que da sustento al Estado moderno. Esto es, al ámbito económico, y que una de sus principales acciones tenga que ver con el aleccionamiento de los sujetos para mantener este orden, cuando los convierte en "cuerpo productivo y cuerpo sometido" (Foucault, 2008, p. 33).

El devenir de los acontecimientos en el departamento de Caldas, en el periodo de tiempo señalado, culminó con la evidencia de las coincidencias discursivas, ergo fácticas, entre los actores sociales que profesan el autoritarismo ultraconservador de extrema derecha, tanto en la legalidad como en la ilegalidad. Dichas coincidencias se pusieron de manifiesto en el escándalo conocido con el nombre de parapolítica, el giro político que tomó esta región del país con la desarticulación de la Coalición, la emergencia de nuevos liderazgos cercanos al discurso paramilitar y la manifestación de la continuidad de esta estrategia político-militar encarnada en las Ilamadas bandas criminales o grupos armados organizados, herederos directos de las AUC.

El artículo está dividido en tres partes. En la primera se aborda el estado de la clase política caldense luego de la separación del Viejo Caldas y la constitución del departamento tal y como se conoce el día de hoy. Esto incluye la fundación del pacto interpartidista conocido como Coalición barcoyepista, episodios de manejo político cuestionable como el robo a Caldas y el desempeño de la alianza liberal-conservadora después de la reforma política, que incluyó la elección popular de alcaldes y gobernadores.

En la segunda parte se exponen los elementos que llevaron a manifestar las primeras fracturas del dominio absoluto de la Coalición, tales como la emergencia de nuevos liderazgos y el impacto de la elección popular. En la tercera parte se presentan los principales episodios de la relación entre políticos y paramilitares en Caldas, que inauguraron el escándalo de la parapolítica en el departamento, en concreto el episodio conocido como el pacto de Caldas, para terminar con la desarticulación formal de la Coalición. El último apartado presenta algunas conclusiones sobre el periodo analizado. 


\section{La clase política caldense después de la escisión}

Una vez formalizada la separación del departamento de Caldas en tres entidades territoriales, la Coalición tuvo vía libre para emerger como la fuerza política dominante del nuevo y más pequeño departamento de Caldas. Los acontecimientos políticos en esta región, a partir de la mencionada escisión, van a tener como protagonista a este colectivo; resaltan hechos de corrupción y manejos electorales aviesos cuando hubo la necesidad de acudir a las urnas para legitimar su poder.

\subsection{Constitución de la Coalición}

A raíz de la secesión del Eje Cafetero, en 1966, la clase política manizaleña tuvo vía libre para disponer del nuevo departamento a su antojo. La época de los Grecocaldenses o Grecoquimbayas, referida a los políticos caldenses de antaño, caracterizados por su elocuencia y erudición, había quedado atrás. Ahora comenzaba la era de los Barrococaldenses, una forma de llamar a la clase dirigente que dispone de su región como de su propio negocio (Jaramillo-Gómez, 2009, pp. 244-245). A partir de aquí se inaugura en Caldas la era del caciquismo (Gutiérrez-Sanín, 2007). El poder político en Caldas (cuyo mapa se muestra en la Figura 1), a partir de la década de 1970, se concentró en manos de políticos profesionales, influyentes en el plano nacional y poseedores de un control administrativo y electoral prácticamente incontestable durante la época de la llamada Coalición barcoyepista, un pacto entre los partidos Liberal y Conservador para repartirse por periodos los cargos públicos del departamento, especialmente la Gobernación de Caldas y la Alcaldía de Manizales (Caicedo-Fraide, 2010, p. 66); 30 años en los que la dinámica política de este departamento estuvo "congelada", tuvo un carácter autorreferido (Gutiérrez-Sanín, 2007), y cuyas instituciones fueron capturadas por este poder parroquial ávido de burocracia (Gibson, 2006), mucho antes de que emergiera el fenómeno paramilitar contemporáneo (Caicedo-Fraide, 2010, p. 107).

El pacto que derivó en la Coalición data de 1978; tanto Barco como Yepes y Giraldo Hurtado ya eran senadores en este año. Los barones liberales tenían un pacto con el conservador Rodrigo Marín Bernal, de la línea laureanistaalzatista (referida al legado de Laureano Gómez y el leopardo Gilberto Alzate Avendaño) y, por ende, de una derecha más alejada del centro, el cual se rompió por falta de entendimiento entre las partes. Fue entonces cuando surgió la posibilidad de hacer el acercamiento con Yepes, otro conservador de la línea ospinista (por Mariano Ospina Pérez, menos radical que Laureano) de centro-derecha y mayoritaria dentro del partido azul. Ya para este momento se hablaba más de alvarismo y pastranismo, tendencias divergentes en el partido azul, encabezadas por Álvaro Gómez Hurtado y Misael Pastrana, respectivamente (GutiérrezSanín, 2007, p. 223). Dicha Coalición se llevó a cabo tanto para mantener un equilibrio de poder en el ámbito local como para lograr una posición influyente con el gobierno nacional, que redundara en favoritismos burocráticos y presupuestales para ellos en el departamento o, dicho de otra forma, coordinar el poder de ambas fuerzas para mantener una correlación estable y favorable a sus intereses (Foucault, 2008; 2007; Deleuze, 1987), lo que implicaba la exclusión de otros actores y la constitución de una forma de autoritarismo subnacional, de acuerdo con Gibson (2006). Así lo describe el propio Omar Yepes:

\footnotetext{
Hoy en día, ni en ese momento, ningún partido político solo estaba en condiciones de dominar con tranquilidad el panorama político regional. Podía ganar el liberalismo o nosotros, pero de todas formas había mucho problema de gobernabilidad... Para evitar esa puja y demás hicimos la alianza, y con el liberalismo, prácticamente en su totalidad, y la mayoría del Partido Conservador en cabeza nuestra, hacíamos un predominio electoral y parlamentario muy alto, entonces con el gobierno nacional no teníamos dificultades para el nombramiento de gobernadores y alcaldes (Hernández-Osorio, 2016, pp. 20-21).
}

El enorme poder político que Barco y Yepes lograron ejercer desde el Senado de la República fue tal que tuvieron una interlocución fluida con el Gobierno Nacional como cabezas visibles y líderes de sus respectivos partidos. Esto re- 


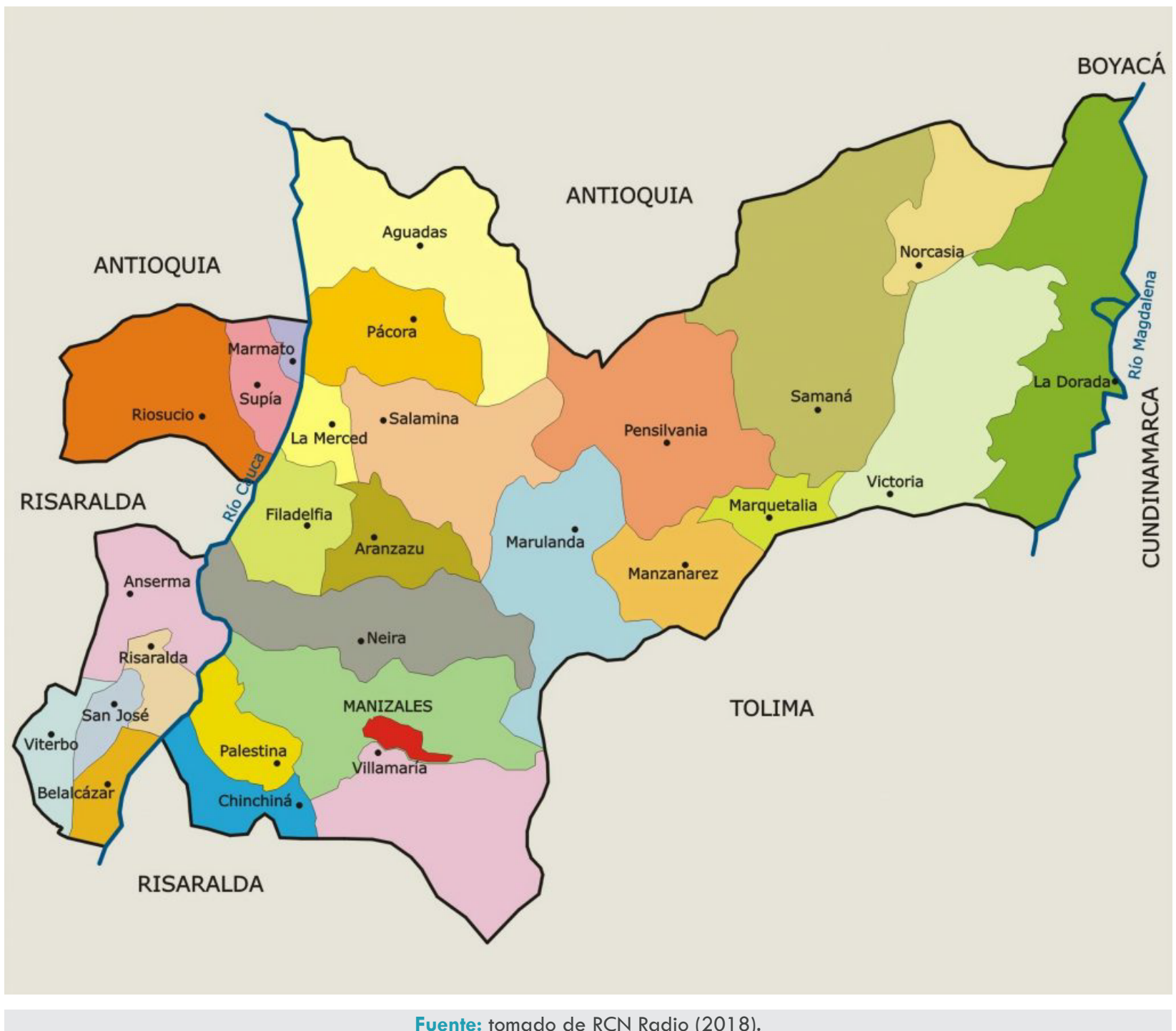

percutió en la posibilidad de entrega de dádivas en los municipios de Caldas y, por ende, en la reproducción de su hegemonía. La constitución de esta élite política, pluralista en teoría, pero monolítica en la práctica, como toda oligarquía (Bobbio, 1982; Bolívar-Meza, 2002), tuvo variadas y negativas consecuencias para el departamento. Entre otras consecuencias se cuentan el cuestionamiento del ejercicio democrático en Caldas, la fractura con las élites tradicionales, el consecuente estancamiento económico de la región, y la popularización y arraigo de prácticas politiqueras, como la compra de votos y el clientelismo (Hernández-Osorio, 2016, pp. 17-18).
Otro aspecto a tener en cuenta sobre la Coalición tiene que ver con el perfil social de sus máximos líderes. En efecto, tanto Barco como Yepes se esforzaron por mostrar su origen humilde, en contraposición con la tradición aristocrática de Caldas, y particularmente de Manizales, en relación con sus élites (Hernández-Osorio, 2016, p. 20). Con esto buscaban ganarse los favores de las mayorías pobres del departamento, lo que a la postre lograron.

A propósito de esto, la política del Viejo Caldas estuvo dominada, desde un año tan remoto como 1850, por las principales 
familias manizaleñas, por la oligarquía comercial-agropecuaria-cafetera-industrial, cuyos apellidos se hacían reiterativos en los cargos públicos y en la escena empresarial privada: Londoño, Alzate, Mejía, Arrubla, Hoyos, Gómez, etc. (Christie, 1986; Ocampo, 1972). A esta generación pertenecieron los famosos (o infames) Leopardos, agrupación política ubicada en el espectro más radical del conservatismo colombiano, caracterizada por sus posiciones falangistas y su elocuencia, representantes puros de los Grecocaldenses y miembros del notablato de este departamento (Gutiérrez-Sanín, 2007).

Durante la década de 1970 aparecen los ya mencionados Yepes y Barco, políticos profesionales que, desde clases medio-bajas, medraron socialmente en la arena política y desplazaron a la oligarquía de antaño; son estos los llamados barrococaldenses. Su ascenso coincide con el escenario propicio para los caciques que legó el Frente Nacional, la escisión de Caldas y el gobierno de Turbay, ejemplo por antonomasia de la forma clientelar de hacer política (Gutiérrez-Sanín, 2007); fue esta la manera como el Frente Nacional delegó en las regiones su poder (p. 327).

La ruptura en la política caldense, en la que la dirigencia económica se apartó del manejo burocrático (Jaramillo-Gómez, 2009), tiene de fondo este cariz clasista. No obstante, la forma como las élites socioeconómicas han influido en la política se ha mantenido: de manera directa, a través de financiación, o como clientes (Gutiérrez-Sanín, 2007, pp. 431 437). La Coalición es la muestra del carácter carente de propiedad y localización del poder (Foucault, 2008; 2007; Deleuze, 1987), toda vez que implicó una ruptura con respecto a una oligarquía que dominó el departamento durante más de 100 años.

Varias formas de oposición surgieron a la Coalición, las cuales estaban de antemano condenadas al fracaso, dado el inmenso poder de su rival. El antecedente más temprano lo constituye la Corporación Cívica de Caldas, organismo creado en 1982, pero cuya trascendencia política fue precaria y efímera (La Patria, 2013). La más destacada y perdurable en el tiempo fue
Actitud Renovadora, colectividad política fundada en 1987, en Pensilvania por Luis Alfonso Hoyos, (Caicedo-Fraide, 2010, pp. 66-67); hijo del reconocido dirigente conservador caldense de Salvación Nacional, Alfonso Hoyos Giraldo, con el apoyo de la acaudalada familia Escobar, a la que pertenece Óscar Iván Zuluaga.

En sus inicios, se identificaron con los postulados filosóficos de Álvaro Gómez Hurtado, fundador de Salvación Nacional, luego de sus desacuerdos con la tendencia oficialista liderada por Misael Pastrana, de donde derivó el Partido Social Conservador (Gutiérrez-Sanín, 2007, p. 225). Su bandera de lucha fue principalmente la denuncia del clientelismo, la corrupción y la politiquería que, según ellos, caracterizaba las actuaciones de la Coalición; la dinámica política los llevó luego a hacer alianzas con partidos y movimientos harto diversos, desde el grupo de Luis Guillermo Giraldo hasta el MOIR y el M-19, además del cuestionado Movimiento del Pueblo, fuertemente vinculado con el paramilitarismo y del que se hablará más adelante. Por lo pronto, tanto la Coalición como sus opositores son ajenos al debate sobre las estructuras armadas, toda vez que en el departamento todavía no son visibles estos grupos, ni en el terreno ni en el discurso.

\subsection{El robo a Caldas}

Caldas fue noticia destacada en el plano nacional a comienzos de la década de 1980. Y no lo fue por algo precisamente loable. En diciembre de 1982, el entonces procurador general de la nación, Carlos Jiménez Gómez, puso a este departamento como ejemplo frente al país, pero para mostrar cómo no debía ser el manejo de la administración pública. En este escándalo se vieron involucrados buena parte de los funcionarios públicos que integraron la gobernación de Carlos Fernando Giraldo Ángel, liberal de la corriente de Luis Guillermo Giraldo y máxima autoridad del departamento entre 1981 y 1982, nombrado por el presidente Turbay. Otros personajes implicados fueron:

(...) los senadores Omar Yepes, Víctor Renán Barco, Dilia Estrada, Luis Guillermo Giraldo, el gobernador Guillermo Ocampo Ospina y otros, con el cual ocurre una pérdida 
de interés en el plano político por parte de la clase dirigente tradicional y una separación entre quienes manejan la empresa privada y quienes manejan la cosa pública (Jaramillo-Gómez, 2009, p. 245).

Valga agregar que este hecho no tuvo ninguna consecuencia política importante, en términos de pérdida de poder por parte de la clase que lo ostentaba (Jaramillo-Gómez, 2009), como lo demuestran la repartición de las alcaldías y la asignación de la Gobernación de Caldas luego de las elecciones presidenciales y parlamentarias de 1986, en las que la Coalición mantuvo su dominio omnímodo.

El robo a Caldas coincidió con la transformación de la élite empresarial en este departamento, ocurrida desde mediados de la década de 1970. Atrás habían quedado las hazañas de los Azucenos, cuyo castillo de arena financiero comenzaba a derrumbarse. A mediados de la década de 1980, emergen en Manizales nuevos liderazgos, a los que se suman otros con cierta tradición, como la Universidad Autónoma, la Corporación Regional Autónoma, el Comité de Cafeteros, La Patria bajo la dirección de José Restrepo, personajes como Pilar Villegas de Hoyos y Ernesto Gutiérrez, para mencionar a los más célebres (Ogliastri y Dávila, 1983). Si bien Jaramillo-Gómez (2009) sostiene que el robo a Caldas significó la ruptura entre élites políticas y empresariales, buena parte de estos nuevos liderazgos tienen estrechas relaciones con los políticos de la Coalición, tanto liberales como conservadores.

\subsection{Desempeño de la Coalición en elecciones populares}

Hacia finales de la década de 1980 se dio en Colombia un hecho significativo en la política nacional: la elección popular de alcaldes y gobernadores, la primera de ellas desde 1988 y la segunda desde 1990. Esta situación cambiaba el panorama político local, toda vez que ahora la Coalición debía buscar votantes para estos cargos administrativos, y lo haría con prácticas que no le eran extrañas: clientelismo y compra de votos. A pesar de los esfuerzos descentralizadores de esta iniciativa, la Coalición mantuvo durante este periodo su posición privilegiada en los focos de poder en Caldas, por medio de prácticas clientelares (Peralta-Duque, 2010, p. 195). Este dominio se extendió a los diferentes concejos municipales y a la Asamblea Departamental, en la que la totalidad de las curules fueron ocupadas por el barcoyepismo (Peralta-Duque, 2010, pp. 209214). Hasta esta fecha, la estabilidad lograda por el despliegue de diversas estrategias de poder (Foucault, 2008) seguía siendo efectiva.

A partir de las elecciones de 1992, se comienza a percibir una pequeña fisura en el dominio oligopólico de la Coalición, lo que demuestra el carácter no esencialista del poder (Deleuze, 1987), con la victoria de candidatos provenientes de colectividades como Actitud Renovadora y el Movimiento del Pueblo (Peralta-Duque, 2010, pp. 215-219). Si bien sobre este último recaen serios reparos por su carácter autoritario y caudillista, en contravía de la intención pluralista de las reformas descentralizadoras (Peralta-Duque, 2010, pp. 218-219).

Esta última colectividad fue fundada en 1987, con el nombre de Paz, Progreso y Cultura, por parte de ganaderos y comerciantes de La Dorada, inconformes con Barco por el incumplimiento de pactos con ellos, en alianza con el narcotraficante Jairo Correa Alzate. En 1990, alcanzaron cuatro escaños para el Concejo Municipal del puerto caldense, y siguieron creciendo hasta llevar a la alcaldía al polémico Nicolás Gómez. Por su parte, Actitud Renovadora llevó en 1988 a la alcaldía de Pensilvania a Jaime Alonso Zuluaga, hermano de Óscar Iván, y asestó un duro golpe a la Coalición y, en particular, al Partido Conservador, que era el dominador en el citado municipio (La Patria, 2013).

\section{Fracturas en la Coalición}

Durante la década de 1990, la política caldense mostró visos de superar la hegemonía barcoyepista, preludio de lo que inevitablemente pasará luego, al tiempo que se perfila un nuevo escenario en las relaciones de poder en Caldas, con la intervención de actores armados y el despliegue de tecnologías disciplinares sustentadas en la violencia física 
(Foucault, 2008). El movimiento Actitud Renovadora comenzó a irrumpir con fuerza en la cerrada contienda caldense. Su líder, Luis Alfonso Hoyos, designó candidatos propios para alcaldías, Gobernación, Asamblea y concejos, en una señal de independencia de la tradicional Coalición, y a pesar de haber nacido en el seno del Partido Conservador. La llegada de Hoyos al Senado, en 1994, representó una primera ruptura de la Coalición, toda vez que asumió dicho cargo sin el aval de los partidos tradicionales (Caicedo-Fraide, 2010, p. 67). A él se le sumó Luis Emilio Sierra, que también llegó al Senado en 1994 y asumió las banderas de Marín Bernal en Salvación Nacional (CaicedoFraide, 2010, p. 67), movimiento que, si bien de casta conservadora, mantuvo distancia con respecto a la oficialidad azul.

En la Asamblea Departamental se constituyó una suerte de alianza de facto entre cinco diputados provenientes de movimientos políticos distintos a la Coalición, para hacerle frente, conformada por Vicente Fernán Arango (Movimiento del Pueblo), Jaime Alonso Zuluaga, Gilberto Posada (Actitud Renovadora), Luis Roberto Rivas (Salvación Nacional) y Pedro Nel García (MOIR). Zuluaga dijo al respecto de esta alianza, conocida en su momento como "los quíntuples": "Estar en un escenario político con Omar Yepes, Renán Barco y Luis Guillermo Giraldo era difícil. Buscamos dar la pelea y hacer oposición y dimos mucho qué decir" (La Patria, 2013, párr. 18). Arango por su parte agregó:

\begin{abstract}
Hicimos una oposición a la maquinaria que tenía montada Ferney Tapasco en la Asamblea. Lo más importante fue un estudio sobre la Licorera en el que destapamos esa olla tan horrible y una reforma a la Contraloría del departamento en donde salieron casi 150 empleados... La batalla en la Asamblea era beligerante, se hablaba un lenguaje de revólver en mano, Tapasco lo ponía encima de la mesa. A diputados les llegó a pegar. O uno pedía la palabra y no la daba (La Patria, 2013, párrs. 16-17).
\end{abstract}

En el plano local, durante el año 1994 La Dorada y Pensilvania son los primeros municipios que se desprenden de la égida de la Coalición. En el primero de ellos, el Movimiento del Pueblo llevó a la alcaldía al padre Nicolás Gómez y, en el segundo, ganó José Jiménez Mejía, por Actitud Renovadora. También en la Asamblea Departamental y el Concejo Municipal de Manizales comenzó a reflejarse el retroceso de la Coalición y el avance de movimientos como el del Pueblo o Salvación Nacional (CaicedoFraide, 2010, pp. 68-69).

Algunos de estos movimientos políticos y militantes se verán involucrados años después en escándalos de relaciones con el paramilitarismo. No obstante, no puede señalarse solo a estos partidos emergentes. Ya desde épocas tan tempranas como 1997, el Partido Liberal, el otro gran señalado, se vio involucrado en este escándalo, si bien los detalles se conocerían más tarde con el caso de los Tapasco. Como ejemplos, el ganador de la alcaldía de La Dorada por este partido, Orlando Echeverri, con el respaldo de Víctor Renán Barco (Caicedo-Fraide, 2010, p. 70), se desmovilizó con las Autodefensas Campesinas del Magdalena Medio (ACMM), en 2006; y Justo Capera, también de la colectividad roja y elegido primer mandatario del puerto caldense en 2008, fue condenado por sus nexos con este grupo paramilitar (Bedoya-Sandoval, 2017).

En el escenario electoral, en 1997, lanzó su candidatura a la Gobernación de Caldas el liberal Tony Jozame, quien años más tarde terminó militando en las toldas del uribismo y enarbolando las banderas del autoritarismo. Por lo pronto, en esta época su discurso iba en la misma línea de la tradicional Coalición, de los fundamentos del Partido Liberal en Caldas y del momento político que vivía el país (La Patria, 2013). Este mismo año, Jorge Enrique Rojas ganó la alcaldía de Manizales por el movimiento Convergencia Popular Cívica, y asestó con esto el primer gran golpe a la Coalición (Caicedo-Fraide, 2010, p. 71; La Patria, 2013), aunque fue destituido un año después.

De aquí en adelante, y hasta el final del periodo abarcado por este artículo, el barcoyepismo no volverá con candidato propio a este cargo público, mientras que el grupo de Adriana Gutiérrez, que ya había sido candidata a la Gobernación en 1992, emergió como alternativa; así, se cuenta la victoria de Germán 
Cardona sobre Arturo Yepes, en cuya primera alcaldía ya había mostrado intenciones de desmarcarse de la Coalición, si bien esta le había dado el visto bueno (Caicedo-Fraide, 2010, p. 87; Jaramillo-Gómez, 2009, p. 247). Este político llegó con el apoyo de un sector del empresariado manizaleño que había abandonado a la Coalición desde la época del robo a Caldas y la emergencia de los barrococaldenses (La Patria, 2013).

En cuanto a la Gobernación de Caldas, la campaña de 2000 mostró el avance del sector autoritario y las fisuras que seguían amenazando la estructura del barcoyepismo. Los candidatos fueron Luis Alfonso Arias, del Partido Liberal y a la postre ganador, y Luis Alfonso Hoyos, líder natural de Actitud Renovadora. A pesar de que Hoyos proviene de familia conservadora, tuvo la oposición de Omar Yepes, quien apoyó a Arias no obstante ser este liberal, y aprovechó para atacar a su rival. Valga decir que las campañas políticas no tenían como eje central el conflicto armado; este tema seguía siendo exótico y visto como periférico en la política caldense, un problema pasajero de pequeñas y alejadas regiones, como el oriente del departamento. Los ataques entre bandos se centraban en acusaciones como malos manejos o inoperancia, y las bondades propias se describían como cambio o experiencia, nada extraño para el escenario político.

En las elecciones regionales de octubre de 2000 , las alcaldías siguieron mostrando la tendencia hacia la pérdida paulatina de poder de la Coalición. De 21 cargos que estaban en disputa, 16 fueron para sus huestes, mientras que cinco fueron conseguidos por otros movimientos, entre ellos el Movimiento Cívico Independiente, nombre electoral de Actitud Renovadora, y el Movimiento del Pueblo, que se impuso en Pensilvania y La Dorada. En este último, se dio la llegada masiva de políticos paramilitares al Concejo Municipal, con Maribel Galvis a la cabeza, además de la cuestionada alcaldía de César Alzate. En estas mismas elecciones, ganó Jairo Alberto Llano en Villamaría, liberal barquista que posteriormente fue condenado por parapolítica. En la Asamblea Departamental también se notó el crecimiento del movimiento de Hoyos, si bien la correlación de fuerzas con res- pecto a la Coalición se mantuvo prácticamente igual. Mientras que, en Aguadas, el candidato conservador de Dilia Estrada, que apoyó a Hoyos a la Gobernación, se impuso sobre el liberal barquista, apoyado por Óscar González Grisales, que varios daban por ganador. La alteración de las relaciones tradicionales de poder como consecuencia del accionar paramilitar comienza a ser notoria en varios municipios de Caldas (Caicedo-Fraide, 2010; Castellanos y Gómez, 2012; Bedoya-Sandoval, 2017).

Ya terminado su periodo en la Gobernación, Tony Jozame lanzó Opción Liberal, un movimiento político inscrito en la línea ideológica del partido rojo, pero independiente de la corriente barquista y de la Coalición, que seguía desintegrándose. Este fue el primer paso de Jozame para abandonar el Partido Liberal y terminar en las toldas uribistas. Ya para el cierre de este periplo es evidente que se está llegando al final de un ciclo y a una ruptura discursiva (Foucault, 2003) en la arena política. Las relaciones de fuerza habían cambiado definitivamente su dinámica, en detrimento de la Coalición y a favor de los grupos emergentes, varios de ellos afines al discurso paramilitar.

\section{Clase política y paramilitarismo en Caldas en el siglo XXI}

La llegada de los grupos paramilitares al departamento de Caldas estuvo acompañada del consiguiente impacto en su clase política. Paralelamente a los acontecimientos militares, a las denuncias de violación de los derechos humanos y al drama de la degradación de la guerra, emergieron las noticias sobre los vínculos de las estructuras armadas con los políticos caldenses y la transformación de las relaciones de poder en el departamento. En este periodo, se asistirá a la desarticulación de la Coalición que durante tantos años dominó el escenario político de Caldas.

\subsection{El pacto de Caldas}

Caldas vivió su propio capítulo de la parapolítica con la revelación de una reunión efectuada 
en la vereda El Tambor del municipio de La Merced, al norte del departamento, controlado por el Frente Cacique Pipintá. Las investigaciones posteriores dieron cuenta de apoyos a políticos del Partido Liberal y el Partido de la U principalmente, para ocupar cargos en el Congreso de la República, la Gobernación de Caldas, la Asamblea Departamental y diferentes alcaldías y concejos municipales. Pero este escándalo no se limitó al norte de Caldas; también tuvo su episodio en el oriente, bajo la dirección de las estructuras que operaban en esta parte del departamento.

Y así se desarrolló el pacto de Caldas, la historia de una alianza que venía de tiempo atrás, pero que, para la prensa, la justicia y la opinión pública surgió en la década del 2000 (López y Sevillano, 2008, p. 69; Sevillano, 2009). También vale decir que, de acuerdo con Ávila (2019), la parapolítica no implicó una renovación de las élites, sino simplemente un reacomodo de las tradicionales a los nuevos retos de la democracia luego de la implementación de la elección popular de alcaldes y gobernadores (p. 344). Sin embargo, en el caso de Caldas se observan varias situaciones. La tesis de Ávila describe perfectamente la situación del Partido Liberal, cuya relación con los paramilitares les permitió recuperar el terreno perdido en La Dorada y mejorar su posición histórica en Aguadas; algo similar puede decirse del Partido de la U, Actitud Renovadora y el Partido Conservador. Pero el Movimiento del Pueblo tiene otras características que lo ponen más cerca de una colectividad propia de élites ilegales emergentes. Se observan así en Caldas las tres variables de políticos en relación con el paramilitarismo que este autor plantea: los más comprometidos con la ideología paramilitar (Galvis y el Movimiento del Pueblo), los tradicionales (la Coalición, particularmente los Tapasco y el Partido Liberal) y los nuevos liderazgos (varios de los que conformaron el Partido de la U).

\subsection{Relaciones de poder en Caldas}

De esta forma, se va configurando en Caldas un panorama completamente diferente con respecto a sus relaciones de poder. La llegada de las estructuras paramilitares a Caldas contó con varias de las características propias del paramilitarismo en el país, como son los vínculos con sectores de las fuerzas militares, presencia de narcotrafican- tes, acciones de exterminio social en las zonas urbanas, repertorios de violencia propios de la estrategia de guerra sucia, etc. (Medina, 1990; Romero, 2003; Zelik, 2015; Velásquez, 2007; Kalyvas y Arjona, 2005; Duncan, 2015; Giraldo, 2004; Rivas y Rey, 2008). De igual manera, implicó un remezón en el tipo tradicional de relaciones de fuerza conocido en Caldas, lo que significó un cambio que tendrá repercusiones durante mucho tiempo después de la reducción de estos grupos. La emergencia de estas estructuras armadas no anduvo independiente de las dinámicas económicas, políticas e incluso culturales en esta región. La huella dejada por el paramilitarismo en Caldas se conserva nítida varios años después de su extinción oficial, como lo evidencia un informe de la Procuraduría en antiguas zonas de dominio paramilitar, entre ellas La Dorada, en el que se afirma que se "ejerció un control social con interrupción en los espacios privados de las víctimas", se evidenció cómo "miembros de la propia comunidad acusaron a sus vecinos", y se practicó una "violencia específica y desproporcionada contra la mujer" (Verdadabierta.com, $2013 b$ ), esto es, se puso en práctica una transformación profunda de las relaciones de poder a partir de dispositivos violentos (Foucault, 2007; 2008).

En el plano político, las alianzas entre políticos profesionales y paramilitares, y la promoción de los primeros a los segundos, ha alterado profundamente los equilibrios en este campo, de forma tal que las castas tradicionales han tenido que ceder su lugar a nuevos liderazgos estrechamente vinculados, tanto de hecho como desde el discurso, con las estructuras armadas. Uno de los cambios más visibles ha sido el del ocaso de la llamada Coalición barcoyepista. Los nuevos liderazgos, por su parte, exponen discursos más cercanos al autoritarismo, y han arrastrado tras de sí al electorado y el empresariado regional, constituyéndose en la nueva fuerza predominante en Caldas. Incluso los partidos tradicionales han aceptado tácitamente su derrota y han optado, en lo que podría entenderse como una táctica de imitación (Gutiérrez-Sanín, 2007), por plegarse a este discurso, lo que los ha llevado a establecer relaciones con los grupos paramilitares, como el emblemático caso del Partido Liberal y la casa Tapasco. "Así pues, esta transforma- 
ción política, económica y cultural a raíz de la emergencia paramilitar es la piedra angular de la nueva Caldas, la Caldas autoritaria que emergió en los años 90 y se mantuvo durante la década del 2000" (Muñoz, 2014, p. 300).

Convergencia Popular Cívica dio avales, junto con Actitud Renovadora, para las elecciones al congreso en 2002 a políticos como Adriana Gutiérrez y Óscar Iván Zuluaga, que luego fueron del Nuevo Partido, más otros candidatos en distintas regiones del país que terminaron involucrados en la parapolítica (Caicedo-Fraide, 2010, p. 66, p. 71$)$. Vale señalar que varios políticos caldenses que hicieron parte de la Coalición fueron adhiriéndose a la causa de Uribe, tales como el otrora liberal barquista Tony Jozame y el barón Luis Guillermo Giraldo (La Patria, 2013). Con la cooptación de los antiguos militantes del Movimiento del Pueblo en Actitud Renovadora, queda consolidado el giro de la fuerza política de Hoyos a la derecha más radical en Caldas junto con el Nuevo Partido, cuyos integrantes dieron luego el paso al Partido de la U.

En 2002, se consolidó la alianza política que desafió a la Coalición, denominada por la prensa local, en un arrebato de originalidad, Coalición B, compuesta por Actitud Renovadora, de Hoyos y Zuluaga, liderada por este último luego de la pérdida de investidura del primero; Convergencia Popular Cívica, la herencia liberal de Fortunato Gaviria, representada por Adriana Gutiérrez; el naciente Nuevo Partido, base del posterior Partido de la U; y, en la mayoría de los casos, Salvación Nacional con Luis Emilio Sierra (Caicedo-Fraide, 2010, p. 82, p. 108; La Patria, 2013), cuyo poder electoral se consolidó y creció en comicios posteriores, con lo que se sella definitivamente la derrota de la Coalición (Caicedo-Fraide, 2010, pp. 92-94, pp. 109-111).

\subsection{La parapolítica y su impacto en Caldas}

En el caso de Caldas, la relación paramilitarismo-partidos políticos asume un curso variopinto. Sus orígenes en el oriente del departamento están vinculados con el Movimiento del Pueblo, el cual se puede clasificar como independiente, cívico y con actitud antipolítica crítica de los partidos tradicionales, principalmente del barquismo (Gutiérrez-Sanín, 2007, p. 401); si bien más tarde el Partido Liberal en La Dorada también transó con los paramilitares. En el resto del departamento, la penetración por el norte se hizo en alianza con la colectividad roja y en detrimento de los conservadores que eran mayoría allí y en general en todo Caldas, y se mantuvo así hasta la desarticulación del Frente Cacique Pipintá. Luego aparecen Convergencia Popular Cívica, el Nuevo Partido y el Partido de la $U$, cuyas huestes también se vieron involucradas en la parapolítica, pero paralelamente a la vinculación con los liberales, lo que desmonta la idea de adopción de un discurso contra los partidos tradicionales. En síntesis, la vocación política partidista del paramilitarismo en Caldas parece haberse desarrollado al margen de pudores ideológicos y con mucha pragmática y priorización de intereses sobre valores, en una especie de actitud agárralo-todo, para acotar la acepción de Otto Kirchheimer.

La llegada del paramilitarismo a Caldas no fue producto del plan de expansión militar de este grupo en los años 90 en su lucha contra la subversión, como ocurrió en los demás departamentos de Colombia, sino que tuvo más tintes políticos y de pugna por el poder oficial, por lo que su presencia se da, de manera consistente, hacia finales de la mencionada década, y se hace notoria a partir del año 2003 con una alianza muy fuerte con la clase política caldense (Sevillano, 2009). Dicha presencia vino por iniciativa de "Ernesto Báez". Su estrategia, según Sevillano (2009), fue similar a la utilizada por alias "Jorge 40" en el Cesar y el Magdalena, la cual consistió en consolidar los Ilamados "distritos electorales" con políticos de la región, que llegaron a ocupar cargos públicos y de elección popular con el apoyo de los paramilitares, y por supuesto con sus correspondientes contraprestaciones.

Gerson Iván Arias Ortiz, de la corporación Ideas para la Paz, agregó en su momento que "Báez" representaba el modo tradicional y clientelista de hacer política, con la diferencia de que lo hace con el apoyo militar del Bloque Central Bolívar (BCB) de las AUC (Gallo, 2006, p. 1B). Parece ser que el escándalo en Caldas 
pudo haber estallado mucho antes de la fecha en que lo hizo, pero el asesinato de Fernando López Ramírez, concejal de Aguadas, en la plaza de mercado de Manizales, el 21 de mayo de 2004, dilató el asunto; aparentemente López Ramírez iba a denunciar los vínculos de políticos aguadeños con los paramilitares (Gallo, 2006, p. 1B; Muñoz, 2014, p. 298).

La sentencia de la Corte Suprema de Justicia contra Dixon Ferney Tapasco, representante a la Cámara por Caldas entre los años 2002 y 2010, y condenado por parapolítica, asegura que este convoca a alias "Alberto Guerrero", luego del asesinato de Óscar González Grisales, también representante a la Cámara y cercano a las AUC de "Báez", para que organice una reunión en la que se mantenga la sectorización política de Caldas (Verdadabierta.com, $2013 a$ ); esta vez garantizada por las armas de las AUC (Verdadabierta.com, 2011).

Cabe agregar que, por el asesinato de González Grisales, "Báez" acusó públicamente al entonces alcalde de Aguadas, Óscar Diego Trujillo Sánchez (El Tiempo, 2005), en pleno proceso de desmovilización con el gobierno de Uribe, y se atrevió a decir: "Yo mismo haría justicia, pero estamos en un proceso de paz. Estamos comprometidos con el gobierno en un cese del fuego... de no ser así, yo mismo le pasaría la cuenta de cobro al alcalde" (Semana, 2005, párr. 1). Reuniones similares a las de El Tambor se llevaron a cabo en otras zonas del departamento, como el corregimiento de Arma en Aguadas y la vereda Miraflores en Villamaría, lugares que fungieron como bases de los paramilitares (Verdadabierta.com, 2009).

La mencionada reunión de El Tambor en La Merced, emblemática en el proceso de penetración del paramilitarismo en Caldas, fue celebrada entre las AUC y representantes de la clase política caldense, y estuvieron presentes, entre otros, "Báez" junto con "Alberto Guerrero" y los políticos Ferney Tapasco, Jairo Alberto Llano, Juan Pablo Sánchez y Enrique Emilio Ángel Barco, todos miembros del Partido Liberal y condenados por parapolítica (El Espectador, 2008; La Patria, 2012). Allí se acordó que las AUC apoyarían la campaña de Ángel Barco a la
Cámara de Representantes por Caldas, a través de, entre otras formas, proselitismo armado en los municipios del norte de este departamento, y que a Tapasco le corresponderían los municipios de Riosucio, Supía, Marmato, Chinchiná y Manizales como parte de su fortín político y electoral (El Espectador, 2008; Caicedo-Fraide, 2010, pp. 124-125), manifestaciones de lo que Álvaro (2008) Ilama clientelismo armado y mafioso. A tal punto llegó la instrumentalización del Partido Liberal por parte del Frente Cacique Pipintá que, según trascendió, "Ernesto Báez" ordenó apoyar a Ángel Barco por encima de la directiva del mencionado partido:
(...) un día lo llamó un amigo y le comentó que están reunidos en el Tambor en el muni- cipio de la Merced, el alcalde, los concejales, Dixon Ferney, Enrique Emilio y Ferney con Alberto, "Ernesto Báez" y toda la cúpula de los paramilitares y que éste último les es- taba dando una orden por que se tenía que trabajar para Enrique Emilio y no por Dixon, que no creyó tal situación porque ya habían puesto los carteles, los pasacalles y a las 8 de la noche llegaron los carros, lo cierto del caso es que al otro día no había nada de Dixon, todo lo habían barrido, la orden era que no podía haber nada que tuviera que ver con Dixon (Caicedo-Fraide, 2010, p. 127).

De hecho, los liberales fueron los más beneficiados con las acciones de los paramilitares, en especial con el asesinato de Iván Rincón Henao, alcalde de Aguadas, en 2003 (Castellanos y Gómez, 2012, pp. 127-128; Muñoz, 2014, pp. 297-298), a pesar que desde el sector liberal se dice que también ellos fueron amenazados y obligados a apoyar a Rincón Henao (Castellanos y Gómez, 2012, pp. 130-131).

Otra de las conclusiones de la reunión de El Tambor fue la creación de una organización estudiantil universitaria Ilamada Fipaz, para lo cual se vinculó a Juan Pablo Sánchez, estudiante de derecho de la Universidad de Caldas y sobrino de Samuel Arturo Sánchez, abogado de "Báez", como quinto renglón a la Cámara por el Partido Liberal (El Espectador, 2008; Verdadabierta.com, 2013a). La gestión de Ángel Barco a favor de las AUC las llevó también a tener presencia en Aranzazu, Salamina y Palestina, poner alcaldes, concejales e incluso 
desviar recursos públicos, como subsidios del SISBEN, a favor de los paramilitares, con la colaboración de miembros de la fuerza pública (El Espectador, 2008; Sevillano, 2009; CaicedoFraide, 2010). Cabe recordar que este político declaró en su momento:

\begin{abstract}
Para nadie es un secreto que el país en general está enfrentando una gran dificultad y existen unas zonas de mucha influencia guerrillera o paramilitar, pero de ahí a que en Caldas se haya aprovechado para sacar unas votaciones altas o para beneficio político propio, no creo que ninguno esté con ese tipo de dificultades (Gallo 2006, p. 1B).
\end{abstract}

El cinismo de estas palabras hace dudar de todas las demás declaraciones en contextos similares. Por su parte, Omar Yepes, a quien Ángel Barco le respondía, afirmaba en un tono más cínico aún, si eso es posible:

En Caldas se oye hablar de que en la zona del oriente y en el norte hay algo de eso, pero no es tan predominante como en otras partes del país. Además, eso es muy difícil que se destape, pues la gente les teme a las represalias por tratarse de pequeñas poblaciones (Gallo, 2006, p. 1B).

La panoplia de opiniones erradas frente a este asunto siguió con el analista Gustavo Duncan, en ese entonces perteneciente a la corporación Seguridad y Democracia, tanque de pensamiento del uribismo. Este autor dijo que la $p a-$ rapolítica en Caldas no iba a ser un escándalo tan grande porque había independencia entre economía y política. Con esto dio a entender equivocadamente que los paramilitares se sustentaban de forma exclusiva en el narcotráfico, y desconoció la financiación de la empresa privada legal (citado en Gallo, 2006, p. 1B).

En el marco de la alianza de políticos caldenses con paramilitares, también trascendió en los procesos de declaración de desmovilizados la cercanía, aún sin aclarar, de los políticos Óscar Iván Zuluaga y Adriana Gutiérrez con Maribel Galvis y los paramilitares de La Dorada (Sevillano, 2009; El Espectador, 2013). En este municipio, fortín político-militar del Frente Omar Isaza de las ACMM, se ha conocido información que compromete a varios reconocidos políticos de la zona y del país por cuenta de la desmovilización de Galvis, expresidenta del Concejo Municipal de La Dorada, militante del Partido de la $U$ y miembro de las ACMM que se desmovilizó con este grupo cuando se empezaron a conocer denuncias en su contra por extorsión (Gallo, 2006, p. 1B; El Espectador, 2013), en una curiosa combinación de todas las formas de lucha practicada por la extrema derecha, pero que está en concordancia con la estrategia de la guerra sucia.

Así se conocieron los nexos aún por aclarar entre los paramilitares, Adriana Gutiérrez y Óscar Iván Zuluaga, más los procesos contra los exalcaldes Jaime Gutiérrez Ángel y César Alzate Montes, también de la $U$, y del liberal Justo Capera Caicedo, sin contar que otro exalcalde, Orlando Echeverri, del Partido Liberal, línea barquista, también confesó haber pertenecido a las AUC y se desmovilizó junto con Galvis (Verdadabierta.com, 2009). A la lista de parapolíticos se suman nombres de alcaldes como Orlando Ríos, de Pácora, Román Aristizábal, de Filadelfia, Henry Ramírez Montes, de Manzanares, Hugo Hernán González Medina, de Marquetalia, Mario Aristizábal, otrora gobernador de Caldas, y hasta el cacique liberal Víctor Renán Barco, cuya investigación se interrumpió por su fallecimiento, entre otros; algunos de los cuales fueron absueltos (López, 2010; López y Sevillano, 2008).

Paralelamente, otro escándalo igual de grave, o aún más, pero menos mediático e investigado, fue el de los empresarios que contribuyeron a la financiación de estos grupos, lo que efímeramente se llamó paraeconomía. En Caldas, se presentaron varios casos en municipios como Aranzazu y Aguadas, donde ganaderos de la región colaboraron voluntariamente con el Frente Cacique Pipintá, así como en Pácora, de parte de un terrateniente involucrado orgánicamente con el mencionado frente, y en La Dorada, como consta en esta declaración de Maribel Galvis:

-«El Estado sabe que ellos han hecho vías de acceso, pavimentaron carreteras, construyeron colegios. Para nadie es un secreto que en San Miguel hay vivienda de interés social construida por ellos». 
-¿Cómo lo hacían?

- «A través de las ferias y fiestas. Convocaban a las comunidades y ellos tomando trago y 'pachanguiando' ponían la plata. A esas francachelas iba mucha gente invitada por el señor [Ramón Isaza]. Todos dejaban su aporte. Allá iban, compartían con ellos... Ahora tiran la piedra y esconden la mano. Ahora todos son santos y el pecador es uno» (El Espectador, 2013, párrs. 20-21).

Sea a favor o en contra de las fuerzas políticas tradicionales, de forma forzada o voluntaria, por acción u omisión, los vínculos entre políticos y paramilitares reconfiguraron profundamente las relaciones de poder en Caldas. Esto se logró por medio de los despliegues microfísicos (Foucault, 2007; 2008; Deleuze, 1987) operados en determinados municipios, en especial del norte y el oriente, principalmente en las zonas rurales, pero también con presencia en las instituciones oficiales ubicadas en los cascos urbanos. Así se logró imponer un discurso autoritario y ultraconservador de extrema derecha que se desperdigó por todo el departamento y que puede calificarse perfectamente como captura y reconfiguración cooptada del Estado (Garay et al., 2008). En este caso, de un departamento.

\subsection{Fin de la Coalición barcoyepista}

El siglo XXI significará el comienzo del fin de la Coalición, algo que se expresará en la pérdida paulatina de algunas alcaldías menores, luego también la de Manizales (Caicedo-Fraide, 2010, p. 71), hasta perder la Gobernación de Caldas en 2013 (Hernández-Osorio, 2016, pp. 25-31; La Patria, 2013). La explicación de este fenómeno está dada por la apertura electoral de finales de los 80 y comienzos de los 90 , el desgaste de la alianza, el retiro de los caciques del Senado y la emergencia de nuevos liderazgos (Jaramillo-Gómez, 2009, p. 247) impulsados bajo la sombra de Álvaro Uribe, más la disidencia conservadora aupada por Luis Emilio Sierra (Hernández-Osorio, 2016, p. 26).

Gutiérrez-Sanín (2007) hace un análisis de caso que no obstante tiene alcance nacional al respecto de la pérdida de poder de los caci- cazgos regionales, y concluye que, además de la apertura electoral, en este proceso tuvieron que ver factores como el aumento desmedido de la demanda clientelar frente a la escasez de los recursos, la desideologización de los partidos y la emergencia de liderazgos atomizados que el autor denomina "operadores locales" ( $p$. 260), los cuales desplazaron el poder de los barones tradicionales. Un análisis que aplica para Caldas y que encaja con la característica del poder constituido desde abajo, de acuerdo con Foucault (2007). También resulta pertinente destacar cómo los liderazgos independientes usaron como una de sus principales banderas de lucha contra la Coalición la denuncia de la politiquería, la cual sin embargo ellos también utilizaron cuando tuvieron oportunidad, en concordancia nuevamente con lo que dice Gutiérrez-Sanín (2007) acerca del deshielo del bipartidismo en el país (pp. 489-498).

Este analista agrega que el fraccionamiento partidista se dio de formas diferentes en las colectividades. En el Partido Liberal, mayoría electoral en el país, ocurrió una implosión fraccionaria que llevó a que aparecieran nuevos grupos en su interior. En el Partido Conservador se dio una explosión que derivó en la aparición de facciones en torno a divergencias ideológicas entre derecha y centro-derecha. A esto se le suma la aparición de movimientos diferentes a los tradicionales (Gutiérrez-Sanín, 2007, pp. 338-339). Para el caso caldense, puede decirse que en lo tocante al partido azul la lectura es aplicable, y pueden incluirse Salvación Nacional (alvarista) y Actitud Renovadora (derivado de Salvación Nacional, pero con un discurso más hacia la derecha). Con la colectividad roja es más difícil encuadrar el marco, lo que puede explicarse porque en Caldas esta era minoría, aunque sí aparecieron grupos como Opinión Liberal, pero de manera tardía. Los independientes siempre fueron minoritarios en el departamento y, salvo Convergencia Popular Cívica, su historia data de los 80 o antes, como el MOIR y la UP.

La revista Cambio emitió una nota llamada El principio del fin, en la que se refiere a esta debacle de la Coalición y menciona varios de los actos ilegales que se le endilgan, entre ellos 
el asesinato de Orlando Sierra y diversos hechos de corrupción. Posteriormente se condenó a Ferney Tapasco como autor intelectual de este asesinato. Si bien la extrapolación entre la Coalición y el Frente Nacional no es completamente dable, sí hay unos puntos convergentes que permiten tener en cuenta dos aspectos que Ilevaron al desgaste de esta última y aplicarlos a aquella. El primero tiene que ver con el descontento que generó en agrupaciones políticas distintas a las integrantes del pacto su exclusión del escenario político, lo que las llevó a organizarse contra este. El segundo es el hecho de que la alianza interpartidista llevó a que ambas colectividades se asemejaran tanto en torno a lo fundamental que se hizo difícil para los electores distinguirlas, y dio pábulo a sus contradictores para denunciar la hegemonía (Gutiérrez-Sanín, 2007, pp. 102-111). Dos escenarios espaciales distintos, una misma explicación plausible.

En las elecciones de alcalde de Manizales, en 2002, ganó Néstor Eugenio Ramírez, de la misma línea que su antecesor Germán Cardona, y derrotó al candidato de la Coalición, lo que ratificó la pérdida definitiva de esta colectividad política en la capital de Caldas. En los comicios para Congreso la tendencia fue similar. Llegó al Senado Óscar Iván Zuluaga y, a la Cámara, Adriana Gutiérrez, además de Óscar González Grisales y Dixon Ferney Tapasco, involucrados en la parapolítica.

El discurso autoritario, de la mano de la campaña presidencial de Uribe, parecía indetenible ahora en la política caldense, y la Coalición se veía cada vez más menguada. También tuvo presencia el radicalismo ultraconservador de extrema derecha caldense en el gobierno de Uribe, representado en Fernando Londoño Hoyos, hecho ante el cual un procaz cronista no dejó de insinuar el retorno de los Grecocaldenses y Leopardos al Congreso, un poco por la retórica y la erudición, pero sobre todo por las ideas que sustentaba.

En la Asamblea Departamental y Concejo Municipal de Manizales se dio el mismo fenómeno, al punto que la Coalición pactó alianzas con el movimiento Equipo Colombia, a la postre des- mantelado por sus nexos con paramilitares. La Coalición solo pudo mantener la Gobernación con Emilio Echeverri. El Nuevo Partido logró consolidarse en el oriente de Caldas con cuatro alcaldías (Samaná, La Dorada, Pensilvania y Marquetalia) y Tony Jozame, ahora en Cambio Radical, ganó con su candidato en Victoria. Más clara fue la correlación de fuerzas de cara a la reelección de Uribe. En aquel momento Caldas apoyó esta candidatura con el Partido de la $U$, representado por Adriana Gutiérrez y Óscar Iván Zuluaga; Salvación Nacional con Luis Emilio Sierra; y Cambio Radical con Tony Jozame.

Es claro que el de la U es un partido que va a acompañar al presidente Uribe, pero no es algo que nazca para una coyuntura de cuatro años sino que nos permita afianzar en el tiempo el modelo de Estado que le ha propuesto Álvaro Uribe al país, un estado comunitario con una alta participación ciudadana (Segura, 2005, p. 6B).

Este pronunciamiento de Adriana Gutiérrez resume las ambiciones del sector político más afín con el proyecto autoritario en Caldas, pues dicho Estado comunitario no es más que su expresión oficial, si bien soterrada. En 2006, también llegó a la política Mauricio Lizcano hijo de Óscar Tulio, retenido por las FARC-EP en 1998- por el Partido de la U y el apoyo de Gutiérrez, Zuluaga y César Alzate. A pesar de la situación de su padre, defendía las banderas de la seguridad democrática y respondía ambivalentemente sobre el intercambio humanitario, diciendo que estaba de acuerdo, pero que Uribe era el hombre que debía encabezarlo, algo que jamás ocurrió. Valga decir, sin embargo, que para otros autores el impulso de los candidatos alternativos a la Coalición con la llegada de Uribe se debe a que ambos sostenían un discurso contra la politiquería (Hernández-Osorio, 2016, p. 31), lo que desconoce las afinidades ideológicas en torno al autoritarismo de extrema derecha.

Un hecho más que socavó la Coalición, sobre todo en lo concerniente al Partido Liberal, tuvo que ver con la ya mencionada revelación de las relaciones entre políticos pertenecientes a esta colectividad y grupos paramilitares de 
la región, lo que también tocó, entre otros, a miembros del Partido de la U (Marín-Correa, 2011), uno de los supuestos nuevos liderazgos regionales. Lo cual confirma que la susodicha alternativa de poder que estos partidos representaban solo significó en muchos casos el regreso de las viejas oligarquías, ahora bajo un discurso autoritario (Ávila, 2019). La pregunta que emerge inmediatamente es por qué la parapolítica afectó a la Coalición y no a los nuevos liderazgos. La respuesta estaría dada por el hecho de que los sindicados y condenados del Partido Liberal fueron más y con mayor visibilidad, pero lo cierto es que este fenómeno definitivamente no es el principal causante del derrumbe de la Coalición.

\section{Conclusiones}

El recorrido hecho muestra con claridad que Caldas vivió una transformación histórica: la Coalición barcoyepista, dueña de la escena política durante más de 30 años (PeraltaDuque, 2010), llegó oficialmente a su fin. Esto no quiere decir que las colectividades que la integraron hayan desaparecido, pero sí vieron su poder bastante menguado. Su lugar fue ocupado por un abanico de liderazgos difícilmente calificables como nuevos, pero sí herederos de las reformas políticas que ampliaron la oferta electoral y contribuyeron a la ruptura del cerrado bipartidismo regional. No obstante, a esta altura debe estar claro que más allá de las buenas intenciones de las sucesivas reformas, en la explicación del deshielo político tiene más poder heurístico el posicionamiento particularista de los intermediarios de los caciques regionales, ahora erigidos líderes en sí mismos tras haberse rasgado la camisa de fuerza del bipartidismo (Gutiérrez-Sanín, 2007).

Entre las colectividades que llegaron a ocupar el lugar de la Coalición hay representantes del discurso autoritario, e incluso personas señaladas de haber tenido vínculos más estrechos con las estructuras armadas. La exposición precedente no deja margen de duda en relación con que el paramilitarismo en Caldas reconfiguró las relaciones de poder en el departamento, en particular en lo que respecta a la representación y posicionamiento de los parti- dos y líderes políticos en sus escenarios naturales de actuación. La incidencia armada tuvo repercusiones directas en municipios como Aguadas, La Merced, La Dorada y Villamaría, por mencionar algunos, y no fue ajena a la Gobernación de Caldas, al menos en el caso de Mario Aristizábal. Los nuevos liderazgos pueden clasificarse, de acuerdo con su nivel de compromiso con los paramilitares, en los más comprometidos, los tradicionales y los nuevos, de acuerdo con Ávila (2019), aunque se aclara que la segunda categoría incluye políticos que adecuaron su discurso al autoritario cuando este estuvo en boga, y otros que simplemente se acomodaron a las nuevas circunstancias, es decir, "camaleones" y pragmáticos. En cuanto a los nuevos, los hubo tanto plegados al autoritarismo como opositores.

Los casos de Salvación Nacional y Actitud Renovadora merecen un trato especial. El primero no mostraba muchas diferencias con las demás colectividades tradicionales e incluso fue a varias elecciones como una parte integrante de la Coalición. Durante el esplendor del autoritarismo fue pragmático, aunque menos protagónico que otras colectividades. En cuanto al segundo, desde su fundación misma este movimiento se planteó la sucesión de la Coalición y se postuló como opción de cambio. En sus inicios, su discurso no mostraba rasgos que permitieran asociarlo con la derecha más radical. Tampoco hay reportes que involucren a la familia Escobar, potentados de Pensilvania que apoyaron a este movimiento, con el brazo armado del autoritarismo en Caldas. La llegada de Uribe a la Presidencia parece haber hecho surgir la vena ultraconservadora en Hoyos y sus partidarios, toda vez que acompañaron entusiastamente esta campaña y a su líder hasta el día de hoy de una forma tan decidida y comprometida que no resulta preciso acomodarlos en la categoría de los "camaleones" o pragmáticos.

Con este panorama se llega a un escenario en el cual el autoritarismo ultraconservador de extrema derecha se posiciona en Caldas, en concordancia con el resto del país, de la mano del entusiasmo generado por la seguridad democrática de Uribe, un político que, no debe haber duda al respecto, representa mejor que nadie los valores e intereses del discurso paramilitar. Con un mayor o menor grado de compromiso, con más o 
menos cercanía ideológica, por convicción, oportunismo o pragmatismo, directa o indirectamente, un porcentaje significativamente alto de la dirigencia política caldense estuvo involucrada con el discurso paramilitar. Esto no quiere decir que se los acuse de paramilitares, lo que para el lugar de enunciación de esta investigación es indiferente, ya que como dice Foucault (2003), los discursos forman sus propios objetos.

Luego sucedió lo inevitable: salió a la luz pública el vínculo orgánico entre políticos profesionales y grupos paramilitares, más allá de las simples coincidencias enunciativas, en un plano que le permitió a la jurisdicción nacional, bajo el postulado de la legalidad (Deleuze, 1987), aplicar sus formas particulares de captación de la verdad, bajo el rótulo de concierto para delinquir en la modalidad de paramilitarismo: la parapolítica (López y Sevillano, 2008; Ávila, 2019). Este escándalo golpeó a Caldas con fuerza y confirmó lo precedentemente dicho: allí fueron involucrados miembros del Partido Liberal, del Partido de la U, del Movimiento del Pueblo, del Partido Conservador...

Existe evidencia de que, en Caldas, se presentó una situación de captura y reconfiguración cooptada del Estado (Gutiérrez-Sanín, 2010; López,
2010; Garay et al., 2008), pero no como departamento en conjunto, sino en algunos de sus municipios, especialmente del oriente y el norte. Así pues, los alcances de la captura y reconfiguración cooptada del Estado en Caldas se quedaron en un nivel bajo, aunque significativo. En cuanto al autoritarismo subnacional (Gibson, 2006), se puede decir algo similar: no es válido postular que todo el departamento estuvo sometido a esta forma de gobierno, pero sí vale afirmarlo con respecto a algunos municipios, básicamente los mismos que tuvieron una presencia paramilitar constante $y$, por consiguiente, capturaron la administración pública.

El dominio político de los liderazgos autoritarios, si bien importante y en constante crecimiento durante el periodo de estudio de esta investigación, no puede compararse con el alcanzado en su momento por la Coalición, su manifestación anterior al arribo de los paramilitares al departamento. Así pues, el grado de autoritarismo subnacional en Caldas, con la desarticulación de la Coalición, de hecho, disminuyó. No obstante, el sector político que la desplazó recurrió a las mismas prácticas de aquella, tales como el caciquismo y el clientelismo (Gutiérrez-Sanín, 2007).

\section{Referencias}

Álvaro, M. (2008). La parapolítica: La infiltración paramilitar en la clase política colombiana. Ánfora, 24(2), 287-305. https://doi.org/10.30854/anf.v15.n24.2008.214

Ávila, A. (2019). Detrás de la guerra en Colombia. Planeta.

Bedoya-Sandoval, J. B. (2017). El poder paramilitar en La Dorada, Caldas. 1992-2002 (tesis de pregrado). Universidad de Caldas, Manizales, Colombia.

Bobbio, N. (1982). Oligarquía. En N. Bobbio y N. Matteucci (Eds.), Diccionario de Política. L-Z (pp. 111 8-1122). Siglo XXI.

Bolívar-Meza, R. (2002). La Teoría de las Élites en Pareto, Mosca y Michels. Iztapalapa, 52(1), 386-407.

Caicedo-Fraide, E. M. (2010). Análisis del mapa político de Caldas. En Misión de Observación Electoral - MOE (Ed.), Monografía político electoral. Departamento de Caldas, 1997 a 2007 (pp. 63-139). https://moe.org. $\mathrm{co} /$ home/doc/moe_mre/CD/PDF/caldas.pdf

Castellanos, J. M. y Gómez, N. (2012). Estrategias de adaptación al conflicto en Caldas. El caso de Aguadas. En W. F. Torres, A. Quiñones, J. M. Castellanos, A. Correa y H. S. Pachón (Eds.), Para vencer el miedo. Respuestas a los impactos de la guerra en el centro y sur de Colombia entre 1980 y 2010 (pp. 106-133). Universidad del Tolima. 
Christie, K. (1986). Oligarcas, Campesinos y Política en Colombia. Universidad Nacional de Colombia.

Deleuze, G. (1987). Foucault. Paidós.

Duncan, G. (2015). Los señores de la guerra: de paramilitares, mafiosos y autodefensas en Colombia. Penguin Random House.

El Espectador. (2008, septiembre 23). Así se repartieron a Caldas. https://www.elespectador.com/impreso/ judicial/articuloimpreso-asi-se-repartieron-caldas

El Espectador. (2013, octubre 29). Origen de la foto con una líder paramilitar que enredó a Óscar Iván Zuluaga. https://www.elespectador.com/cromos/actualidad/articulo-148617-origen-de-la-foto-unalider-paramilitar-enredo-a-oscar-ivan-zuluaga

El Tiempo. (2005, marzo 27). Los torcidos hilos del poder en Aguadas Caldas. https://www.eltiempo.com/ archivo/documento/MAM-1640984

Foucault, M. (1985). Saber y verdad. Las ediciones de la piqueta.

Foucault, M. (2003). La Arqueología del Saber. Siglo XXI.

Foucault, M. (2007). Historia de la sexualidad I: la voluntad de saber. Siglo XXI.

Foucault, M. (2008). Vigilar y castigar. Nacimiento de la prisión. Siglo XXI.

Gallo, J. P. (2006, diciembre 3). Parapolítica, destape que puede salpicar a Caldas. La Patria, p. 1 B.

Garay, L. J., Salcedo, E., De León, I. y Guerrero, B. (2008). La captura y reconfiguración cooptada del Estado en Colombia. Fundación Método, Fundación Avina y Transparencia por Colombia.

García-Peña, D. (2005). La relación del Estado colombiano con el fenómeno paramilitar: por el esclarecimiento histórico. Análisis político, 53(1), 58-76.

García-Pérez, P. (2016). La privatización de la violencia en Colombia y las AUC: de las autodefensas al paramilitarismo contrainsurgente y criminal. Izquierdas, 27(2), 230-255. http://dx.doi.org/10.4067/ S0718-50492016000200009

Gibson, E. (2006). Autoritarismo subnacional: estrategias territoriales de control político en regímenes democráticos. Desafíos, 14(1), 204-237.

Giraldo, J. (2004, agosto). El paramilitarismo: una criminal política de Estado que devora el país (blog). https://www.javiergiraldo.org/spip.php?article76

Gutiérrez-Sanín, F. (2007). ¿Lo que el viento se llevó? Los partidos políticos y la democracia en Colombia (1958-2002). Norma.

Gutiérrez-Sanín, F. (2010). Reflexiones a propósito del libro "Y refundaron la patria...". En C. López (Ed.), Y refundaron la patria... De cómo mafiosos y políticos reconfiguraron el Estado colombiano (pp. 9-28). Penguin Random House.

Hernández-Osorio, C. J. (2016). Cuando caen los caciques. Razones del auge y declive de la coalición barcoyepista en Caldas. Una mirada desde la literatura sobre política subnacional. Escribanía, 13(2), 11 34.

Jaramillo-Gómez, O. (2009). La formación socioeconómica de Caldas y sus características políticas. Virajes, $11(1), 229-253$.

Kalyvas, S. y Arjona, A. (2005). Paramilitarismo: una perspectiva teórica. En A. Rangel (Ed.), El poder paramilitar (pp. 25-45). Planeta.

La Patria. (2012, septiembre 30). 29 meses saboreando la paz en La Merced. https://www.lapatria.com/ caldas/29-meses-saboreando-la-paz-en-la-merced-16119 
Sociedad y Economía N`43 (Mayo - Ago 2021) / e-ISSN: 2389-9050 / e1039779 Julio Cruz

La Patria. (2013, septiembre 1). 26 años de intentonas contra Barco y Yepes. https://www.lapatria.com/endomingo/26-anos-de-intentonas-contra-barco-y-yepes-42378

López, C. (2010). "La refundación de la patria”, de la teoría a la evidencia. En C. López (Ed.), Y refundaron la patria... De cómo mafiosos y políticos reconfiguraron el Estado colombiano (pp. 29-78). Penguin Random House.

López, C. y Sevillano, O. (2008). Balance político de la parapolítica. Arcanos, 14, 62-87.

Marín-Correa, A. (2011, mayo 22). El entramado de la parapolítica en Caldas. El Espectador. https://www. elespectador.com/content/el-entramado-de-la-parapol\%C3\%ADtica-en-caldas

Medina, C. (1990). Autodefensas, paramilitares y narcotráfico en Colombia: origen, desarrollo y consolidación: el caso Puerto Boyacá. Documentos periodísticos.

Melo, J. O. (1990). Los paramilitares y su impacto sobre la política colombiana. En F. Leal-Buitrago y L. Zamosc (Eds.), Al filo del caos (pp. 475-514). Tercer mundo.

Muñoz, F. G. (2014). Los impactos del narcoparamilitarismo sobre la convivencia comunitaria en Aguadas, Caldas (1999-2006). Revista de paz y conflictos, 7, 279-309. https://doi.org/10.30827/revpaz.v7i0.1797

Ocampo, J. F. (1972). Dominio de clase en la ciudad colombiana. Oveja Negra.

Ogliastri, E. y Dávila, C. (1983). Estructura de poder y desarrollo en once ciudades intermedias de Colombia. Universidad de los Andes.

Peralta-Duque, B. (2010). La descentralización municipal y su relación con la autonomía local y el desarrollo sociopolítico en el departamento de Caldas, 1988-2000. Jurídicas, 7(1), 182-230.

RCN Radio. (2018). Caldas, el segundo departamento más seguro de Colombia. https://www.rcnradio.com/ mcontent/5b36b55d5f0049e5d12fa02b/amp

Reyes-Posada, A. (1991). Paramilitares en Colombia: contexto, aliados y consecuencias. Análisis político, $12(1), 35-41$.

Rivas, P. y Rey, P. (2008). Las autodefensas y el paramilitarismo en Colombia (1964-2006). Confines, 4(1), 43-52.

Romero, M. (2003). Paramilitares y autodefensas: 1982/2003. IEPRI.

Segura, A. (2005, diciembre 4). Uribe, con contrapeso en Caldas. La Patria, p. 6B.

Semana. (2005, marzo 27). El de Aguadas. https://www.semana.com/nacion/articulo/el-aguadas/71653-3

Sevillano, O. F. (2009, febrero 27). El pacto de Caldas. Verdadabierta.com. https://verdadabierta.com/elpacto-de-caldas/

Velásquez, E. (2007). Historia del paramilitarismo en Colombia. História, 26(1), 134-153. http://www.scielo. $\mathrm{br} / \mathrm{pdf} / \mathrm{his} / \mathrm{v} 26 \mathrm{n} 1 / \mathrm{a} 11 \mathrm{v} 26 \mathrm{n} 1 . \mathrm{pdf}$

Verdadabierta.com. (2009, mayo 18). Parapolítica apenas empieza sus estragos en Caldas (La Patria). https://verdadabierta.com/parapolitica-apenas-empieza-sus-estragos-en-caldas-la-patria/

Verdadabierta.com. (2011, septiembre 6). Ramón Isaza aceptó 27 delitos en Caldas. https://verdadabierta. com/ramon-izasa-acepto-27-delitos-en-caldas/

Verdadabierta.com. (2013a, agosto 20). Parapolítica: Dixon Ferney Tapasco Triviño. https://verdadabierta. com/parapolitica-dixon-ferney-tapasco-trivino/

Verdadabierta.com. (2013b, diciembre 27). Las víctimas de alias 'Gurre' siguen sufriendo hoy. https:// verdadabierta.com/las-victimas-de-alias-gurre-siguen-sufriendo-hoy/

Zelik, R. (2015). Paramilitarismo. Violencia y transformación social, política y económica en Colombia. Siglo del hombre. 